\title{
Automatic Irrigation System Using Wireless Control
}

\author{
Muhammad Rusydi Muhammad Razif ${ }^{1 *}$, Preetharan Ravindran ${ }^{1}$, Ili Najaa Aimi Mohd Nordin ${ }^{1}$ and \\ Nor Saradatul Akmar Zulkifli ${ }^{2}$
}

${ }^{1}$ Faculty of Engineering Technology, Universiti Tun Hussein Onn Malaysia, Pagoh, 84600, Muar, Johor, Malaysia. ${ }^{2}$ Faculty of Computer System \& Software Engineering, Universiti Malaysia Pahang, Lebuhraya Tun Razak, Gambang, 26300, Kuantan, Pahang, Malaysia.

*Corresponding author: rusydi@uthm.edu.my

\begin{abstract}
Traditional methods of irrigation and fertilizing is very time consuming for farmers. Over-irrigation as well as leaching of fertilizers below the root zone, erosion, and transport of soil and chemical particles to the drainage ditches can increase energy and water consumption in farming. A single systems combining irrigation and fertilizing will greatly reduce the cost and time needed in farming. There are two types of fertilizers available for home gardener - granular and water-soluble fertilizers. Generally, granular fertilizers release nutrient gradually but can last longer than water-soluble fertilizers. This project will provide an automated system for irrigation and fertilizing for plantation using Arduino as the microcontroller. This system will include a mobile application to control the amount of water during the irrigation and fertilizing processes. The microcontroller communicates with the mobile application via internet using the Wi-Fi modulator. Then, the microcontroller processes the information and operates the irrigation and fertilizing pumps which supplies water and fertilizer through the sprinkler system in the field. Any feedback will be sent to the user through the mobile application.
\end{abstract}

Keywords: Irrigation, fertilization, mobile application, wireless control, plantation.

(C) 2019 Penerbit UTM Press. All rights reserved

Article History: received 4 September 2019; accepted 1 December 2019; published 24 December 2019.

\section{INTRODUCTION}

Agriculture is a source of life necessity for human being. So a variety of modern technologies have been developed to make the agriculture work easier for the farmers. This technology is mainly concerned on the aspect of environment friendly and cost saving. The project will be focused on one of the important part of growing plantation which is the plants fertilizing process. There is some process to be conducted before supplying the fertilizer to the plantations. This works such as the fertilizer need to be mixed with the suitable amount of water before being supplied to the plants and also it needs to be done by timing to ensure the good condition of the plantations.

The process of agriculture needs some man power depending on the size of the plantation and also consuming large amount of time whereby it could be used for some other work. So this project describes an automatic fertilizer system where this system could do the process by itself without the interference of human. To control the system, IoT has been used because of in a survey been done where when the farmers are not around the work cannot be carried out which makes their plant unhealthy which effects its output.

So IoT system will be the solution so the work can be done without the presence of the person physically.

The irrigation process requires human energy (amount depends on size of the plantation) for a simple work, it is also a time consuming job which could be used for better work. Other than that, those farmers having problem to fertilize their plantation when they have other daily commitments to be executed and this will affect the plantation [1]. Moreover, they also having problem in mixing correct amount of water and fertilizer. There are bad consequences if higher amount fertilizer is mixed which could increase the acidity of the soil and kill the plants on the other side if less fertilizer is mixed it will lead to lack of nutrition for the plants [1]. Wastage of water and fertilizer also sometimes happens which will increase their cost.

Many methods and different types of system have been implemented to develop this type of automated system as for example system proposed by other is where it has separate control of water and the fertilizer [1]. But this system is not suitable for this condition because there would be a situation where if fertilization needed but the soil moisture status is high it will affect the effectiveness of fertilizing because of liquid fertilizer is used in this case.

Over-irrigation can increase energy consumption and water cost as well as leaching of fertilizers below the root zone, erosion, and transport of soil and chemical particles to the drainage ditches. Irrigators who monitor soil moisture levels in the field greatly increase their ability to conserve water and energy, optimize crop yields, and avoid soil erosion and water pollution. But the aspect of fertilizing is not considered here, whereby the watering 
affects the effectiveness of fertilizer to act upon the plant. Both of the process should work together in a system to maintain the best result of a plantation [2].

Irrigation and fertilizing of large agricultural operations is expensive and greatly affects the environment. There is a continuing demand to conserve ground water by more efficient irrigation and for a reduction in the pollution of these waters due to fertilizing. An additional economic benefit is achieved when the irrigation water is optimized, and the energy usage and proper amounts of fertilizer are optimized. In the past, it has been common to operate irrigation systems by timing devices which method does not take into account the actual need of the soil for moisture. There have been developed systems which utilize various types of buried sensors to determine when the soil requires irrigation. In general, most systems utilize an in-ground sensor or probe, a threshold device which will turn on the irrigation below a certain indicated moisture level and timers.

However, the readings from commonly used moisture sensors are greatly influenced by the salinity of the soil as well as by the moisture. Therefore, the operation of such systems will be influenced by the operator fertilizing schedule [6].

Other than that flow of fertilizer or water present invention relates generally to the regulation. A consumer must choose between what is thought to be the most dangerous parameter to measure. Further, consumers must purchase different systems for detecting different types of dangerous parameters and controlling the shut off of different types of supply lines [7].

No matter how hard one tries, it's tough to transform the topic of fertilizers into lively conversation. But for all gardeners, knowledge of fertilizers and how to apply them effectively is as crucial to vigorous plant growth as knowing a plant's hardiness zones. So in the interest of growing healthy plants, what follows is a brief discussion of the why, what, how, and when of applying these chemical elements. Three prime chemical elements are commonly found in all mixed fertilizers are $\mathrm{N}, \mathrm{P}$ and $\mathrm{K}$. The functions of these chemical elements are $-\mathrm{N}$ for Nitrogen, promotes healthy leaf growth by stimulating the production of chlorophyll (the main chemical involved in photosynthesis - how plants convert sunlight to food); $\mathrm{P}$ for Phosphorus supports the vigorous development of roots, stems, blossoms, and fruits; $\mathrm{K}$ for Potassium, plays a key role in helping plants digest and manufacture their foods.

All of the nutrients essential to plant growth are present in the soil or are floating in the air. However, not all plants can access the key nutrients found in the soil or in the air. Each soil type has its own mix of nutritional ingredients, so before considering what fertilizers a plant may require, we need to consider the soil in which a plant is growing [3].

Activities like intensive farming, construction, and traffic can alter soil chemistry and structure, limiting the nutrients that plants can use. In some cases, the nutrients aren't naturally existing to begin with or have been leached out over time. For these reasons, the diggers of the dirt and keepers of the garden, must replenish, replace, or help to release elements that are beyond the reach of the plants.

When it comes to fertilizing, more does not necessary mean better because of much fertilizer can damage of even kill the plants [3]. Before applying any fertilizer, it's a good practice to have the soil tested. There are two types of fertilizers available to the home gardener: granular and water soluble [4]. Each type has its advantages and disadvantages. Granular fertilizers deliver food to a plant slowly but have the advantage of longevity. Since they must be dissolved by water before a plant can use them, granular fertilizers do not leach out of the soil as rapidly as water-soluble types. Water-soluble fertilizers are faster acting but more transient, which means they must be applied more frequently than the granular type [4]. Both types of fertilizers are effective, depending on condition either we need to give our plants a quick but frequent fix or a sluggish but extended feeding.

There are several ways to apply granular and watersoluble fertilizers, but there are a few general guidelines that one should follow when applying them. Avoid applying a fertilizer on windy or rainy days because it the fertilizer will be misplaced and ineffective. When using a granular fertilizer, always be sure to knock the fertilizer off plant leaves to avoid burn [5]. Never apply a granular fertilizer when the soil is extremely dry, and water it in thoroughly after applying to prevent plant burn.

IoT is the network of everyday objects, physical things embedded with electronics, software, sensors, and connectivity enabling data exchange. Basically, a little networked computer is attached to a thing, allowing information exchange to and from that thing [7]. Be it light bulbs, toasters, refrigerators, flower pots, watches, fans, planes, trains, automobiles, or anything else around, a little networked computer can be combined with it to accept input (especially object control) or to gather and generate informational output (typically object status or other sensory data). This means computers will be permeating everything around us, ubiquitous embedded computing devices, uniquely identifiable, interconnected across the Internet [7]. Because of low-cost, networkable microcontroller modules, IOT is really starting to take off. Through this IoT device, we are able to monitor the efficiency of the system whether the system is functioning according to the specified setting that is implemented onto the system. The fertilizer and the water level are mixed to a specified level and controlled by Arduino and sends the signal to ESP8266 which will in turn transmit data to the user through Wi-Fi connection.

By integrating the automatic irrigation system with IoT, the system brings a change to management of field resources where Arduino is used to control the system developed through programming language by providing the tools necessary to control the fertilizing system. The application makes use of Wi-Fi feature of mobile phone as a solution for the fertilizing and irrigation control system. This system covered lower range of agriculture land and able to determine the level of fertilizer and water that is needed to be mixed for a proper irrigation to the plants. An android application is discovered to overcome excess mix of fertilizer and water, under irrigation or over irrigation that causes leaching and loss of soil nutrient. 


\section{METHODOLOGY}

In the beginning of the project all the data's which is essential for developing this project need to be collected. Afterwards electric circuit need to be design as a second step and it need to be tested as it is connected correctly and in right manner. A hardware need to be interfaced with a microprocessor which will act as the brain of the systems. The next step is to write a coding as the system's process instruction. After writing the code is finished, the program will be uploaded in Arduino microprocessor and interfaced with the hardware. As both of it is interfaced the system need to work according to the planned system. If there is error, it needs to be troubleshooting until the desired system is achieved.

This system can be switched $\mathrm{ON}$ by internet through mobile application known as Blynk. As the system is switched ON, the pump at the fertilizer tank will be activated and pump the liquid fertilizer to the mixing tank until the set quantity of fertilizer is pumped. Immediately as the set fertilizer quantity is pumped the fertilizer pump will switch off and simultaneously water pump will switch on and pump the water to the mixing tank. The amount of water to be supplied will be twice the amount of fertilizer.

The formula inserted in the software is Total amount of fertilizer times two equal to the total amount of water. When both fertilizer and water is filled in the mixture tank, the mixture pump will switch on and pump out the mixture to the plantation. The amount of mixture need to be pumped out is set by Equation (1), where $M$ is the amount of mixture pumped, $F$ is the total amount of fertilizer and $W$ is the total amount of water.

$$
M=\frac{3}{4}(F+W)
$$

ESP8266 NodeMCU Wi-Fi Module is a self-contained SOC with integrated TCP/IP protocol stack which can give any microcontroller access to Wi-Fi_33 network. The ESP8266 NodeMCU is able of either hosting an application or offloading all Wi-Fi networking functions from another application processor. Each ESP8266 NodeMCU module comes pre-programmed with an AT command set firmware, means it can be simply hook this up to Arduino device and get about as much Wi-Fi_33ability as a Wi-Fi_33 Shield offers. The ESP8266 module is an highly cost effective board with a huge, and ever growing, community.

Water flow sensor consists of a plastic valve body, a water rotor, and a hall-effect sensor. When water flows through the rotor, rotor rolls. Its speed changes with different rate of flow. The hall-effect sensor outputs the corresponding pulse Signal.

Connecting the water flow sensor to Arduino requires minimal interconnection. Connect the VCC (Red) and GND (Black) wires of the water flow sensor to the $5 \mathrm{~V}$ and GND of Arduino, and link Pulse Output (Yellow) wire of the water flow sensor to Arduino's digital input pin water flow sensor and it draws a maximum of $15-20 \mathrm{~mA}$ at $5 \mathrm{~V}$ DC input.

Blynk is a Platform with Android applications to control
Arduino, Raspberry $\mathrm{Pi}$ and other microcontroller's software over the Internet. It is a digital dashboard where we can build a graphic interface for our project by simply dragging and dropping widgets. Blynk is not tied to some specific board or shield. Instead, it's supporting hardware of our choice. When Arduino is linked to the Internet over Wi-Fi, ESP8266 chip, Blynk will be active online and ready for IoT connections.

The electrical connection of the circuit is made of three main platforms, which are relays, Arduino Uno and ESP8266. The relay is connected from $240 \mathrm{~V}$ AC power supply to the water pumps of each container. Arduino Uno and ESP8266 NodeMCU are connected from 5V power supply DC power supply to the flow sensors. Figure 1 shows the complete electrical circuit connection of the prototype.

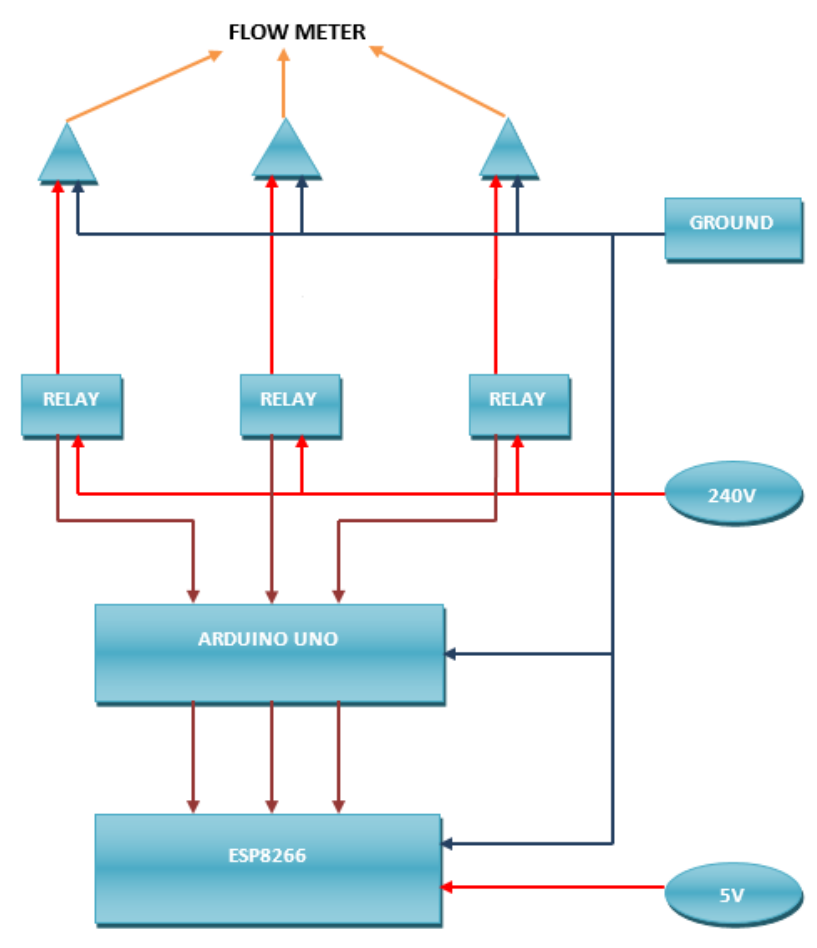

Figure 1. The electrical connection of the project

System verification is a step to ensure that this project meets the requirement that has been designed since the planning stage. It is essential to validate the task that has been executed to confirm that there is no issue with the device when evaluating its functionality. A number of tests have been decided to verify functions in the project. Those preliminary evaluation works as planning to build the hardware. This system has a few verifications.

The first verification of this system is to build an automated fertilizing and irrigation System prototype, whereby water flow meter, Arduino Uno microcontroller are being used with other minor supporting electronic items, such as the pump is replaced with LED to be tested.

The second verification of this system would be to verify whether the system works as desired, like does Arduino sends signal to close the pump when enough water and fertilizer is flowed through the water flow meter. In order to develop the prototype model, three container made of plastic measuring $30 \times 12 \mathrm{~cm}$ are used as water, 
fertilizer and mixture tank storage. It is sufficient to store the amount of liquid fertilizer and water to demonstrate the working process of the system. Besides that, it will be much easier to because it is light weight material. A PVC pipe of $35 \mathrm{~cm}$ vertical length and $6 \mathrm{~cm}$ horizontal length is connected to each other and placed in all three plastic containers. The PVC pipe from the mixture container is extended to be connected to the sprinkler in order to have a more realistic representation of the fertilizing system.

In order to have an observable and clear output, the water pump plays a major role in this project. Thus, all the connections made must be made properly so that the prototype can function the way it is designed. For real implementation of this project water pump with $8 \mathrm{Hp}$ can be used for one acre of plantation. For this project, an aquarium water pump was used to represent the real water pump. Since there will be a total of three pump, all together three water flow sensor were required to develop the prototype. PVC pipe at the mixture container to the sprinkler were used as the representative of HDPE pipe. The flow meter and the water pump were connected to the Arduino Uno. The hardware electrical connection is shown in Figure 2 and the pipe and flow sensors connection is shown in Figure 3.

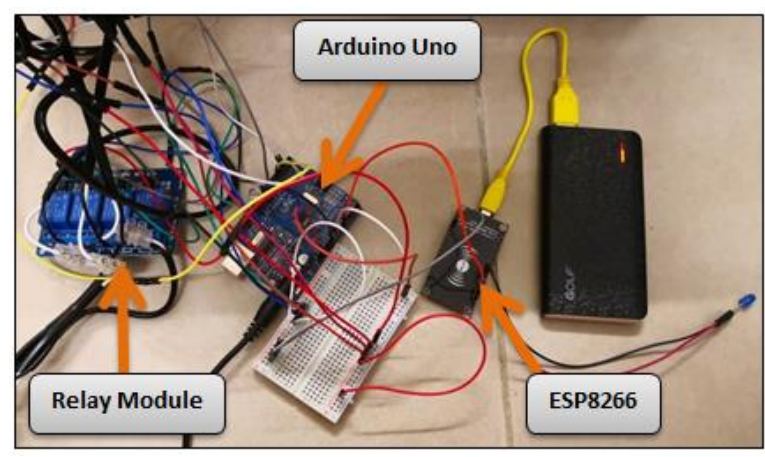

Figure 2. The hardware electrical connection of the prototype

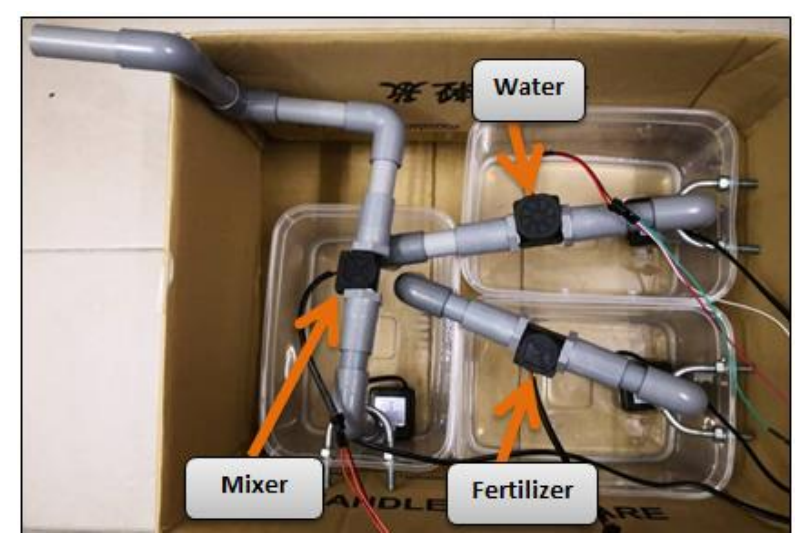

Figure 3. The pipe and flow sensors connection for the prototype

The methodology of the project is being portrayed on this chapter. The development of this device is separated into two parts, which are hardware and software development. The hardware is built and developed using electronic items such as water flow sensor, LED, resistor, microcontroller. On the other hand, the software is developed using the Arduino 1.6.8.

\section{RESULTS AND DISCUSSION}

The values obtained through sensors enable the system to switch the pumps on and off. A farmer can remotely monitor the irrigation process on the farm. Table 1 depicts the readings of the three water flow sensors set with certain initial values. The readings were taken over a period of two minutes to observe the rate of flow of mixture when the pumps are $\mathrm{ON}$.

Table 1. Readings of the three water flow sensors set

\begin{tabular}{|c|c|c|c|c|}
\hline $\begin{array}{c}\text { Volume } \\
\text { of } \\
\text { fertilizer } \\
\text { flow out } \\
\text { from the } \\
\text { system } \\
\text { (mL) }\end{array}$ & $\begin{array}{c}\text { Volume } \\
\text { of water } \\
\text { flow out } \\
\text { from the } \\
\text { system } \\
\text { (mL) }\end{array}$ & $\begin{array}{c}\text { Volume } \\
\text { of } \\
\text { mixture } \\
\text { flow out } \\
\text { from the } \\
\text { system } \\
\text { (mL) }\end{array}$ & $\begin{array}{c}\text { Time } \\
\text { taken for } \\
\text { the } \\
\text { mixture to } \\
\text { flow out } \\
\text { from the } \\
\text { system }(\mathrm{s})\end{array}$ & $\begin{array}{c}\text { Rate of } \\
\text { flow of } \\
\text { mixture } \\
\text { flow out } \\
\text { from the } \\
\text { system } \\
(\%)\end{array}$ \\
\hline 200 & 400 & 450 & 45 & 75 \\
\hline 300 & 600 & 675 & 60 & 75 \\
\hline 400 & 800 & 900 & 75 & 75 \\
\hline 500 & 10000 & 1125 & 90 & 75 \\
\hline 600 & 12000 & 1350 & 105 & 75 \\
\hline
\end{tabular}

The rate of mixture flow out from the system is calculated using formula of (Volume of mixture) / (Volume of fertilizer + Volume of water) $\times 100 \%$. The rate shows a steady percentage of 75 , which means the rate is constant throughout the system as the values are set in Arduino. The rate of the flow of the irrigation system is exhibited by graph using volume versus time representation as shown in Figure 4 below. It is essential to know how well the system functions, so this graph representation is made to display the performance of the system.

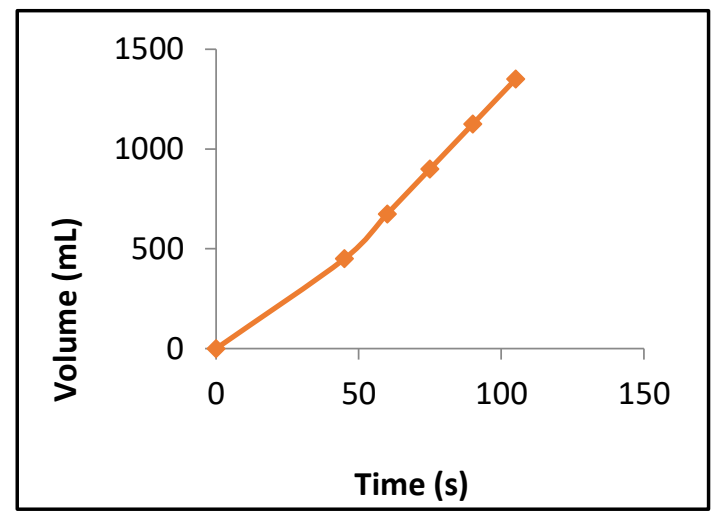

Figure 4. Volume versus time graph representation

From the graph at Figure 4, it is noticed that the volume of the mixture in the container is directly perpendicular to the time taken for the mixture to flow out of the container. This shows that the system is working fine as the rate of flow of the irrigation system is maintained at percentage of 75 . 


\section{CONCLUSION}

The designed prototype of an automatic irrigation system was able to work in sequence. On top of that, the system was also able to interact with IoT to initialize the system where the ON signal is given from mobile. After completing the one cycle sequence, the system will OFF. Next ON signal given will resume the normal operation again. The system will always be ready to STOP the system when it detects a signal from the Blynk software from mobile at all times.

The amount of fertilizer, water and also the sequence of mixing the liquid fertilizer worked automatically as presumed without any need of human intervention. The microprocessor was programmed precisely with all the steps bit sequence. Since it works without any help it could safe time, energy and cost for the user.

The method to create this system is decided because of the cheaper cost compare to any other mechanical or electronic device usage. Besides that, this system is just need to made small change to be implemented in real life such as the pump, piping sprinkler and also the water flow meter type which will be more suitable for the usage and environment condition. By having a lower cost means that, the prototype can be developed in a bigger number thus can be implemented in more locations so that, the effectiveness of this device can be determined.

Although all the hardware are working fine, the system is not ready to be implemented directly as it is currently at plantation area since the suitability of environment condition and amount of usage which is suitable need to be considered. Thus, a large size, longer pipes and suitable instruments needs to be used replacing current instrument before it is implemented into real life plantation. Moreover, the amount of fertilizer and water set in the program is suitable for the prototype and demonstration purpose.

For the long term development of this project, future researchers can explore new methods to control the amount of fertilizer and water to be adjusted directly by user.
Beside that it can be improved on the data displaying part. This method was omitted the display part because the main intention was to make a system which can ON and OFF using IoT from wherever. From that, the farmer can concentrate more on other work and save cost.

\section{ACKNOWLEDGMENT}

This research is fully supported by TIER 1 grant, H136. The authors fully acknowledged Ministry of Higher Education (MOHE) and Universiti Tun Hussein Onn Malaysia for the approved fund which makes this important research viable and effective.

\section{REFERENCES}

[1] A. Semwal and G. R., "Automatic irrigation and fertilization system using Arduino and GSM SIM module," in International Journal of Science and Research, vol. 6, no. 2, pp. 765-769, 2017.

[2] Raut, Ashwini, M. Panse, D. Chaware and A. Koparkar, "Sensor based automated irrigation system," in International Journal of Engineering Research \& Technology, ISSN (2015): 2278-0181.

[3] Tang, Qi-Zhan, Z. Tian, S. Zhu, and Y. Deng, "Effect of liquid fertilizer made from sugar mill based distillery effluent on sugarcane," in Sugar Tech 8, no. 4 (2006): 303-305.

[4] Miller, Richard N. and K. Bruce Ray, "System for optimum irrigating and fertilizing," in U.S. Patent 4,545,396, issued October 8, 1985.

[5] D'antonio, Nicholas F., Robert Giggey and Richard O. Colvin, "System for controlling fluid flow," in U.S. Patent 6,123,093, issued September 26, 2000.

[6] G. Romain, "Control system for the irrigation of watering stations," in U.S. Patent 5,740,031, issued April 14, 1998.

[7] Sebilo, Mathieu, B. Mayer, B. Nicolardot, G. Pinay and A. Mariotti, "Long-term fate of nitrate fertilizer in agricultural soils," in Proceedings of the National Academy of Sciences 110, no. 45 (2013): 1818518189. 